\title{
Effectiveness of Writing Groups in Nursing Homes
}

\author{
Katherine P. Supiano \\ Ronald J. Ozminkowski \\ Ruth Campbell \\ Carole Lapidos \\ University of Michigan Medical Center
}

\begin{abstract}
We examine the effect of participation in an 8-week writing group in six nursing homes. Pretest and posttest assessments of cognitive and affective functional status were administered to 62 participants and 54 control subjects. We asked writing-group participants about previous writing experience and perceived ability to convey feelings, ideas, life experiences, and memories to others. Weekly assessments were conducted on eight group process measures. Findings suggest that participation in writing groups may reduce depression, particularly among residents with higher cognitive ability and greater depression. Significantly more participants than control subjects report an ability to relate feelings and ideas to other residents and staff. Improvement in group process measures is greatest for cognitively impaired participants and those with high physical function scores. There is considerable improvement in residents for whom writing-group participation frequently is considered inappropriate: those without writing experience, the depressed, and the cognitively impaired.
\end{abstract}

In recent years, the focus of nursing-home activity program development has shifted from number and variety of activities to value and meaning of activities. Shore (1978) described group activities in nursing homes as evolving from "the recognition that the aged would enjoy and benefit from recreation and entertainment" (p. 344) to an awareness of "the sustaining value of the group experience" (p. 346). Concern that the primary emphasis in activity programming was limited to entertainment or crafts resulted in an effort to develop enrichment programs in nursing homes. Two ideas are inherent in the concept of enrichment: residents are encouraged to assume active, meaningful roles, and resi-

AUTHORS' NOTE: This work was supported by a grant from the Office of Services to the Aging, State of Michigan (384601), 1987.

The Journal of Applied Gerontology, Vol. 8 No. 3, September 1989 382-400

- 1989 The Southem Gerontological Society 
dents are regarded as individuals with a unique past and potential for creative mental activity.

Writing groups are among the several programs which aspire to provide enrichment. Since Koch (1977) began teaching poetry writing in nursing homes, and Kaminsky (1974) began leading writing groups in New York senior centers, groups of this kind have increased in popularity. According to Campbell (1985), "the success of this type of group for the elderly may lie in its underlying assumption that despite the decline and loss present in aging, there are also positive changes, opportunities for creativity, growth, and wisdom" (p. 547). Coberly, McCormick, \& Updike (1984) described the writing group as "a class that capitalizes on a lifetime of fine work as a proper subject for art. Writing allows older adults to continue to enjoy a sense of being the acting agent instead of the acted upon" (p. 1).

The value of writing groups is threefold. First, writing offers a unique means of self-expression. Campbell (1984) observed that "through writing, most often autobiographically, the writers select from their experience in a more conscious fashion than they would during oral reminiscence and thus recreate their own identities" (p. 139). That writing provides a creative quality lacking in oral reminiscence was observed by Coberly et al. (1984): "If one remains muddled in nostalgia, or if one insists on literally transcribing things as they say they really were, he misses the excitement of transforming experience into art" (pp. 2-3). Second, writing produces a tangible product, "an effort of individuals to grant permanence to valued ideas" (Getzel [1984], p. 193). Finally, there is value in writing with others, for others, and with the feedback of others. Kaminsky (1974) noted, "One of the most vital things that happens in the poetry group is that several individuals discover that they are not alone in feeling as they do. . . barriers come down, and the sense of isolation gives way to a sense of community" (p. 89). The dynamics that characterize writing groups go beyond finding a common ground in shared experience; "gradually older writers will come to value not only their similarities, but their differences, each unique viewpoint, descriptive eye, narrative gift. Soon, they exchange their comfortable addiction to an idealized past for the tangible pleasure and artistic satisfaction of creating in the present a specific, vivid real past" (Coberly et al., p. 3). 


\section{Method}

While much effort has been expended in the development of writing groups in nursing homes and curriculum guides for writing teachers (Coberly et al., 1984; Koch, 1977), little attention has focused on measuring the groups' effectiveness or on identifying which residents benefit most from participation.

The study reported here examines the effect of participation in a writing group on nursing home residents. The evaluation is conducted on three levels. First, pretests and posttests (of participants and a control group) assess the effect of participation on affect, depression levels, and cognitive function. Second, the effect of participation is evaluated weekly on a checklist of group process measures. Third, before and after participation, residents are administered a questionnaire regarding their attitudes toward and experiences with writing.

We hypothesized that the creative process of writing in a group setting would increase affect scores and lower depression levels, improve communication and group skills, and increase participants' interest in writing. We also intended to examine how residents of different functional abilities were affected by participation.

The writing groups were developed as one component of a largescale nursing-home enrichment program coordinated by Turner Geriatric Services, University of Michigan Medical Center, with funding from the Michigan Office of Services to the Aging. The program includes memory training classes and life-review interviews, as well as writing groups. Writing group participants were recruited from six area nursing homes (four proprietary, two nonprofit). The program coordinator invited 62 participants to "a writing get-together, a chance to share ideas, listen to great poetry, and try your hand at it." The primary selection criterion was physical; any resident with the strength to participate in an hour-long class was welcome. Recruitment was extended beyond the active residents to include disoriented and depressed residents and those who participate in few activities; we hoped thereby to obtain information on who was best served by this program.

The 54 residents in the control group were selected from a pool of residents who were considered appropriate for participation by the program coordinator and nursing home staff but who chose not to attend the group. Although this selection was not a truly random sample, both controls and participants were similar across baseline measures. The 
selection process also reflects the reality of group activities in nursing homes, in that participants self-select or are chosen for inclusion by staff. Moreover, for ethical reasons, participation was open to all residents.

Each writing group had 8-10 participants. In the week before the first group session, we pretested writing and control subjects, using the Mini-Mental State Examination (MMS) (Folstein, Folstein, \& McHugh, $1975)$ to assess cognitive functioning, the Geriatric Depression Screening Scale (DS) (Yesavage et al., 1983) and Affect-Balance Scale (AB) (Bradburn, 1969; Moriwake, 1974) to assess affective functioning, and the Rapid Disability Rating Scale (ADL) (Linn, 1967) to assess physical functioning. In addition, a questionnaire developed for this project assessed the utility of writing by inquiring about previous reading and writing habits and the perceived ability to use writing to convey feelings and ideas, life experiences, and memories to family/friends, nursing home staff, and other residents. The instructor and trained volunteers administered this 14-item questionnaire at the beginning of the first session. Weekly, the instructor assessed group process measures of the writing group including appearance, awareness of self and others, interest, participation, enjoyment, paying attention, verbal communication, and nonverbal communication (Burnside, 1978). Limited resources precluded collection of utility-of-writing data from the control group. Also, since the control group did not participate in any intervention other than regularly scheduled activities, group process data are not available for them. Though this may limit the generalizability of our findings in these areas, our results suggest hypotheses which others may test in a controlled experimental setting.

An 8-week writing group was conducted in each of the six nursing homes. An instructor with a master's degree in counseling and human development and several trained volunteers taught the sessions. The curriculum included collaborative poetry and individual poetry and prose. Themes of weekly sessions included childhood experiences, nature, seasons, love, music, memories of war and the Depression, and aging (see Appendix). Sessions began with the instructor or author reading aloud any writing done during the previous week. The instructor introduced the subject for the week, then read aloud poetry or prose on that theme or in that style. Large-print copies of all materials read were provided. After discussion, participants received their assignments and wrote in class. Given the frail condition of many participants, volunteers assisted in transcribing, repeating, challenging, and shaping 
the work of the writers. Participants completed at least one assignment, frequently two, in class. The instructor gathered assignments and read them aloud, and residents and volunteers offered comments. Comments by the instructor and volunteers focused on the writing rather than on the writer. Clarity of ideas and richness of description were emphasized. Homework assignments were provided each week for participants desiring them. In each session, participants received typed copies of the classwork and homework done during the previous week. At the conclusion of the course, writings were collected into an anthology for each home.

Over the eight weeks, a gradual shift from collaborative to more individual writing occurred. Topics became less general and more personal, and a transition from descriptive to expressive writing was encouraged. Increasingly, dialogue between participants was facilitated as the group became more cohesive.

During the week following completion of the writing group, assessment of both groups of subjects by the MMS, DS, and AB measures was repeated. We used pairwise $t$ testing to determine differences between pretest and posttest means. We compared writing group members and controls to see if participation resulted in significant changes in cognitive or affective mental functioning. To determine whether highfunctioning residents respond differently from low-functioning residents to the enrichment activity, controls and participants were stratified into functional categories. To accomplish this stratification, we used pretest scores on the three mental functioning tests and on the physical functioning indicator (ADL) to distinguish high- and low-functioning groups. We used paired $t$ tests to assess differences in pretest and posttest means, and we compared participants with relevant control group members. ${ }^{1}$

We hypothesized that major gains from pretest to posttest would be more likely for participants in the low-functioning groups, as they had the most potential for improvement. Modest gains were expected for high-functioning participants. We expected high- and low-functioning control subjects to show either no significant changes from pretest and posttest or modest declines in functioning over the eight weeks.

Finally, to assess changes in attitudes about the utility of writing, we conducted binomial tests of symmetry between pretest and posttest responses to the writing group questionnaire. 


\section{Results}

The average age of participants was 82.3 years; that of control subjects was 84.7 . The ratios of women to men were $79.2 \%: 20.8 \%$ for writing groups and $70.6 \%: 29.4 \%$ for control groups. Mean educational levels were 12.3 years (participants) and 12.6 years (controls). The average length of stay in the nursing homes was 28.5 months for participants and was 26.0 months for the control subjects. Mean ADL scores were 35.8 for control subjects and 33.54 for participants ( 236 is normal for nursing home residents) (Linn, 1967).

There was some attrition from the writing group. The reasons were death $(n=1)$, discharge from the nursing home $(n=1)$, dropout from the writing group $(n=9)$, and inability to posttest residents because of illness or refusal to answer questions $(n=9-15)$ after multiple attempts. This would be problematic if those tested had not represented participants in the writing group or control subjects.

To investigate the missing data problem, we compared those who were tested with those who were not in terms of a number of demographic variables. For each group, we found only two significant differences $(p<.05)$. Writing group members who were not posttested were younger and more likely to be male. There were no significant differences in educational level, length of stay in the nursing home, family size, percentage widowed, previous residence, or percentage who "typically participate" in nursing home activities. Control group members who were not posttested came from larger immediate families and had spent less time in the nursing home. No other significant differences were found. While those who were not posttested may have been less tolerant of the intrusion associated with the testing procedure, the lack of patterns similar to the missing data in the groups and the fact that few significant differences were found leads us to believe that failure to test some residents did not result in samples of respondents who are dissimilar to their respective writing or control groups.

\section{Difference Among Nursing Homes}

We conducted an analysis of variance of pretest and posttest means for control and writing groups in each of the six nursing homes. To guard against a false declaration of significance in multiple comparisons of nursing homes, we used Bonferroni's procedure (Neter \& Wasserman, 1974). The results show no significant differences in aver- 
age levels of physical and mental functioning among nursing homes in either the control or the writing groups, and therefore the six nursing homes are combined in further analyses.

\section{Changes in MMS, DS, and AB Scores}

We performed pairwise $t$ tests to determine significance in pretest and posttest means. We found no significant change in cognitive status in either control or writing group subjects. Whereas control subjects showed no change in depression scores from pretest to posttest, writing group subjects showed a decline in depression which approaches significance at the .05 level (less depression), $\left(\overline{\mathrm{x}}_{\text {diff }}=1.02, p<.08\right)$. We noted no change for either group on the AB.

To compare high- and low-functioning residents, we conducted pairwise $t$ tests for significant differences from pretest to posttest. In the subgroup analyses, $p$ values approaching .05 were observed. Given the small sample sizes in these subgroups (Table 1), such findings are remarkable, and those instances in which $p$ values are less than .05 are significant.

When we analyzed high- and low-functioning groups, we found several important or significant differences. Of these, more emphasis should be placed on those with the smallest $p$ values because the large number of comparisons investigated makes the finding of spurious results more likely. Writing group subjects with high MMS scores showed improvement in DS scores which approached significance $\left(\overline{\mathrm{x}}_{\mathrm{diff}}=1.04\right.$, $p<.08$ ). Those with high DS scores (greater depression) demonstrated significant improvement in DS scores at posttest $\left(\bar{x}_{\text {diff }}=2.86, p<.03\right)$. Similarly, subjects with low AB scores (poorer affect) showed significant improvement in $\mathrm{AB}$ at posttest $\left(\overline{\mathbf{x}}_{\text {diff }}=1.72, p<.0001\right)$. Finally, those with high AB scores showed an improved DS score $\left(\overline{\mathrm{x}}_{\text {diff }}=.83\right.$, $p<.09)$. It is also noteworthy that no significant changes were observed in MMS, DS, or AB scores as a function of high ADL versus low ADL functional levels. Control group members did not exhibit similar changes in functioning, and this suggests that participation in the writing group is the causal factor.

In addition, several control group members showed a decline in affective functioning which did not occur among writing group participants. Control group members with low cognitive functioning, those with high affective functioning, and those with less depression showed significant or important declines in affect $\left(\overline{\mathrm{x}}_{\mathrm{diff}}=1.06, p<.02 ; \overline{\mathrm{x}}_{\mathrm{diff}}=1.00\right.$, 


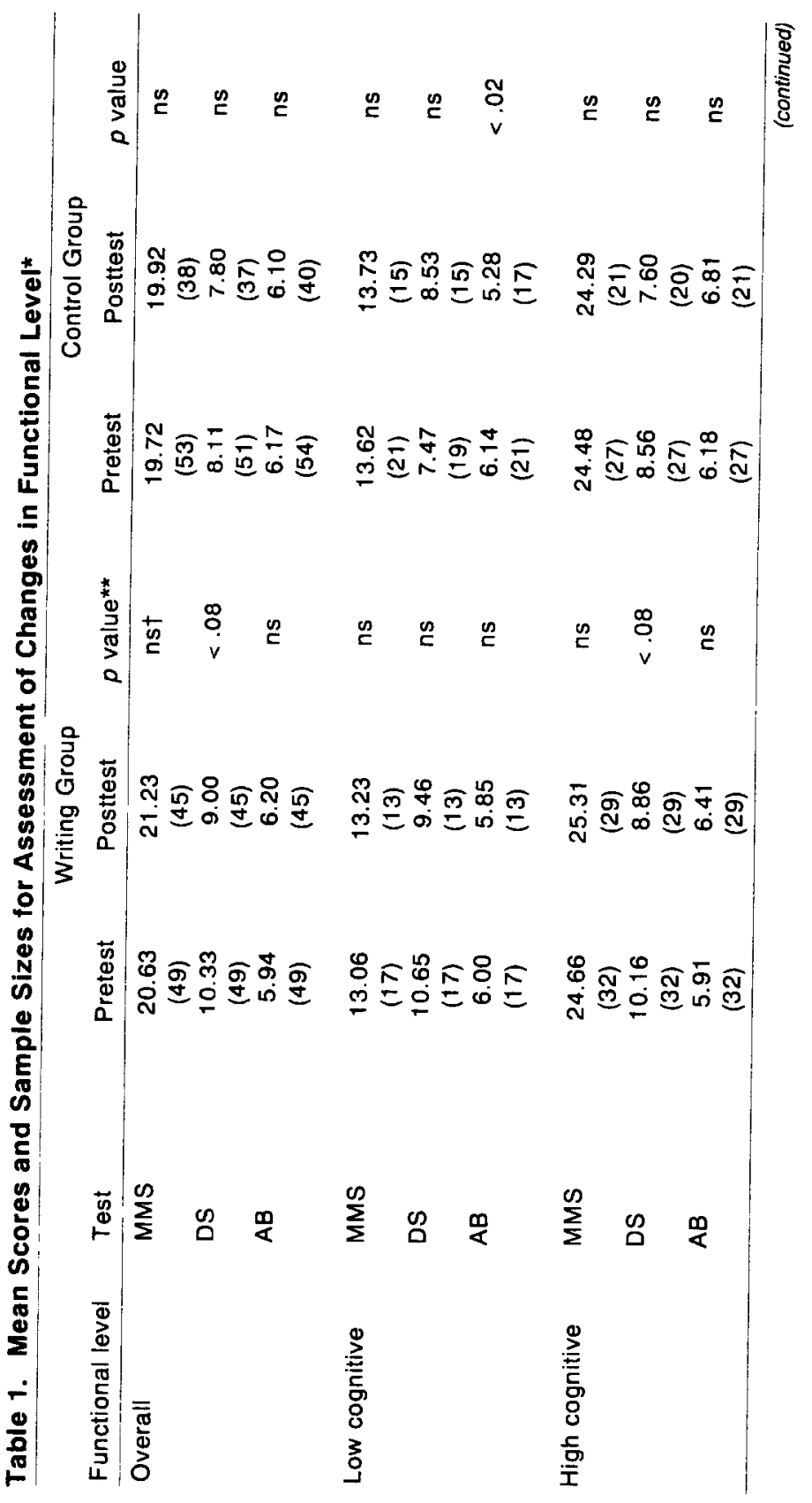




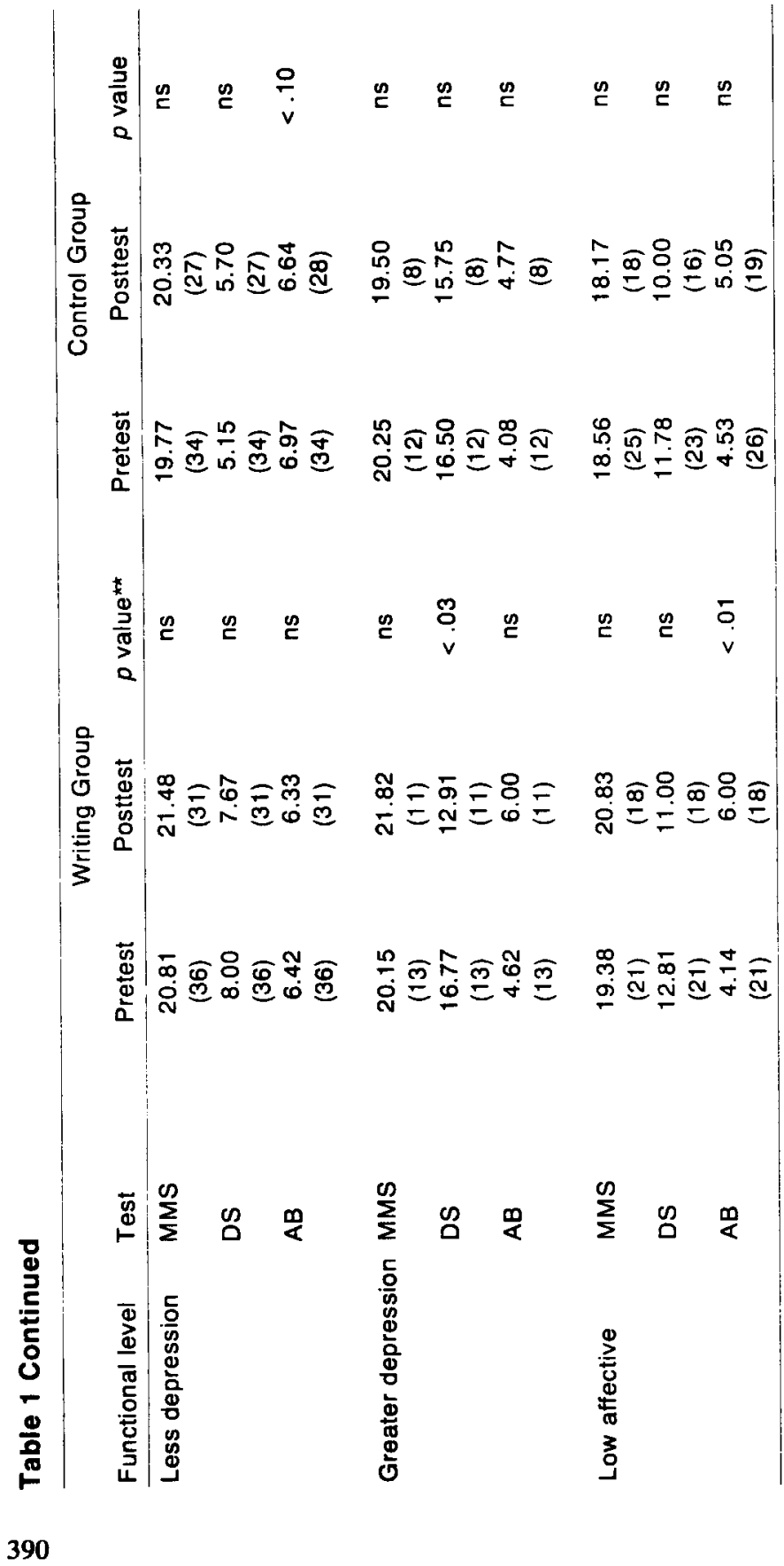




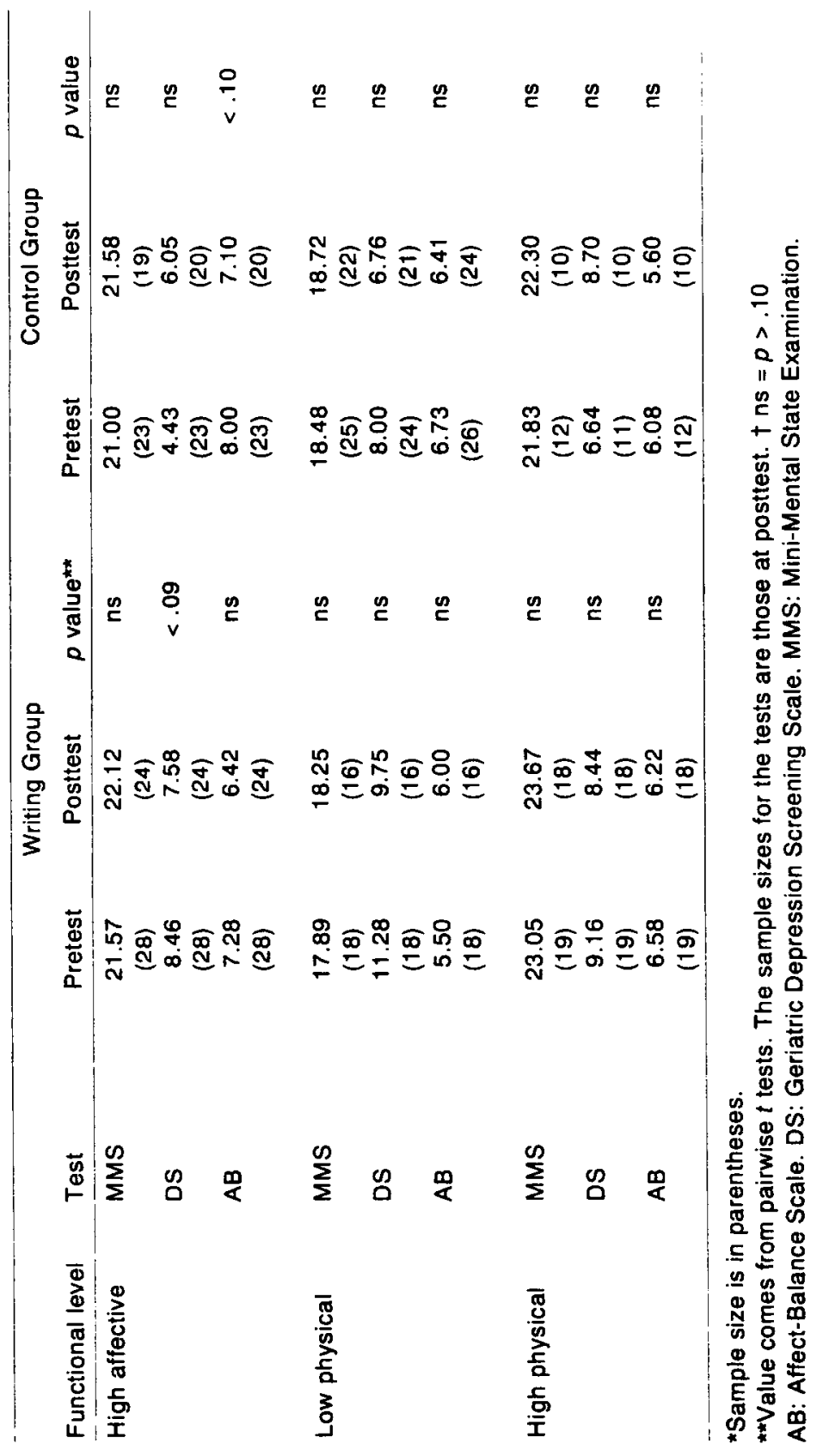


$p<.01 ; \bar{x}_{\text {diff }}=.05, p<.10$, respectively). The fact that these declines did not occur among writing group participants suggests that the writing group may also be effective at postponing functional declines.

\section{Writing Group Questionnaire}

Half of the participants in the writing group had had previous writing experience and half had not. Of those with any such experience, $63.2 \%$ did not write on any regular basis and $31.6 \%(\mathrm{n}=7)$ had written regularly. The majority of participants had not kept a journal or diary at any time. Most had neither a desire to write a book nor any experience with creative writing classes.

In determining the nature and purpose of their writing, participants were asked when and why they wrote. At posttest, significantly more participants indicated that they wrote when happy $(p<.0001)$, that writing helped work out problems $(p<.0001)$, and that writing helped focus thoughts $(p<.0001)$. No change was noted in the "writing when sad" query (Table 2).

We asked four questions at pretest and posttest to determine perceived ability to convey feelings/ideas and life experiences/memories to significant others. On completion of the writing group, participants were significantly more likely to perceive themselves as able to share feelings and ideas with other residents and to relate life experiences and memories to staff and other residents (Table 2).

When asked more directly about the impact of writing, significantly more participants stated at posttest that writing could help convey feelings and ideas $(p<.0231)$ and life experiences and memories $(p<.0001)$ to others.

At posttest, $54.3 \%$ of participants reported doing additional writing outside of class. Fifty percent of participants indicated discussing or sharing their writing outside of class.

\section{Group Process Measures}

The weekly assessments of appearance, awareness of self and others, interest, participation, enjoyment, attention, relating to others, verbal communication, and nonverbal communication were recorded by scores of poor, fair, or good. To discern trends in group process, comparisons between the first and second 4-week periods were made. The mechanism for comparison is designed to reduce the likelihood that changes 


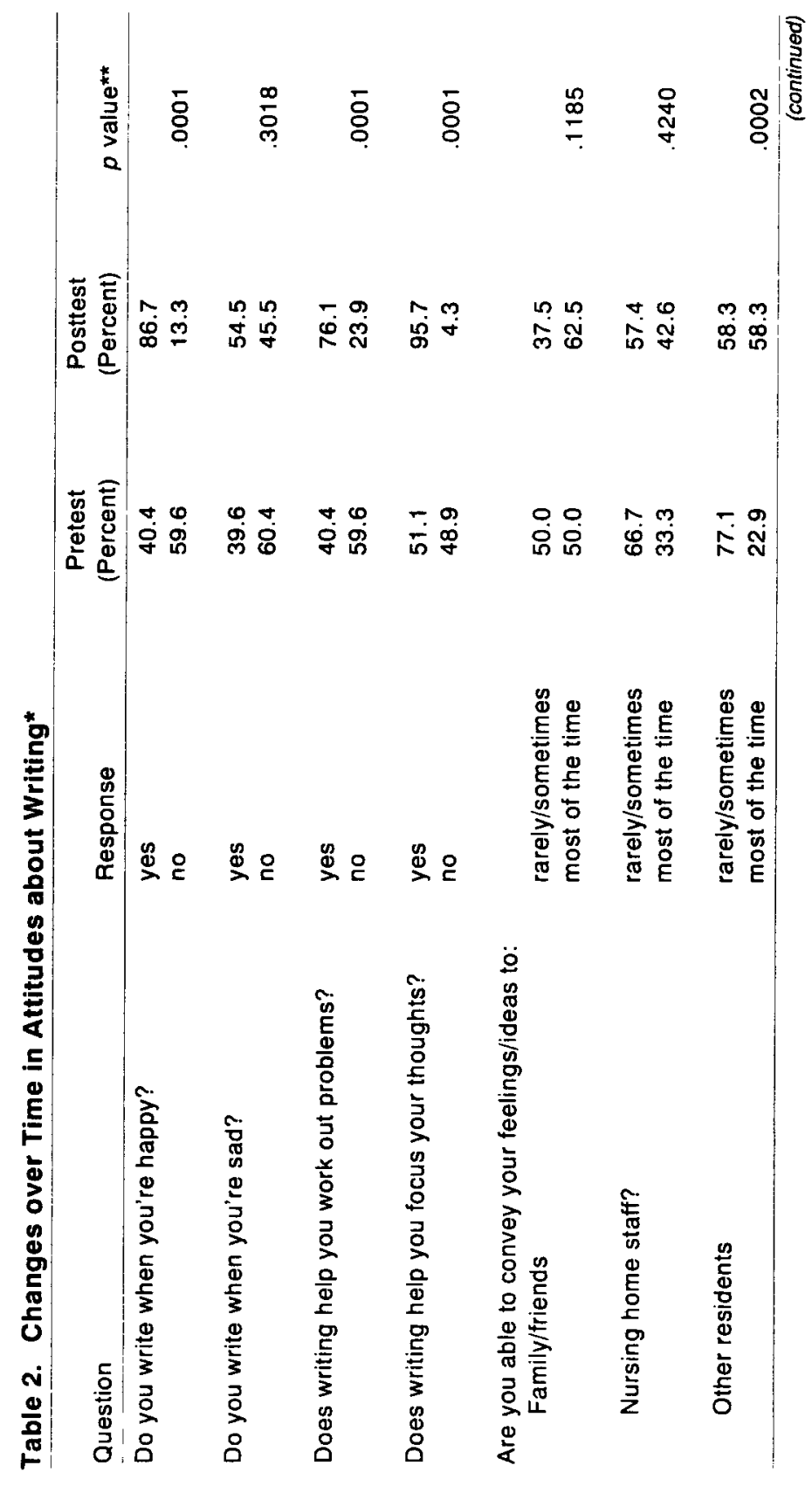




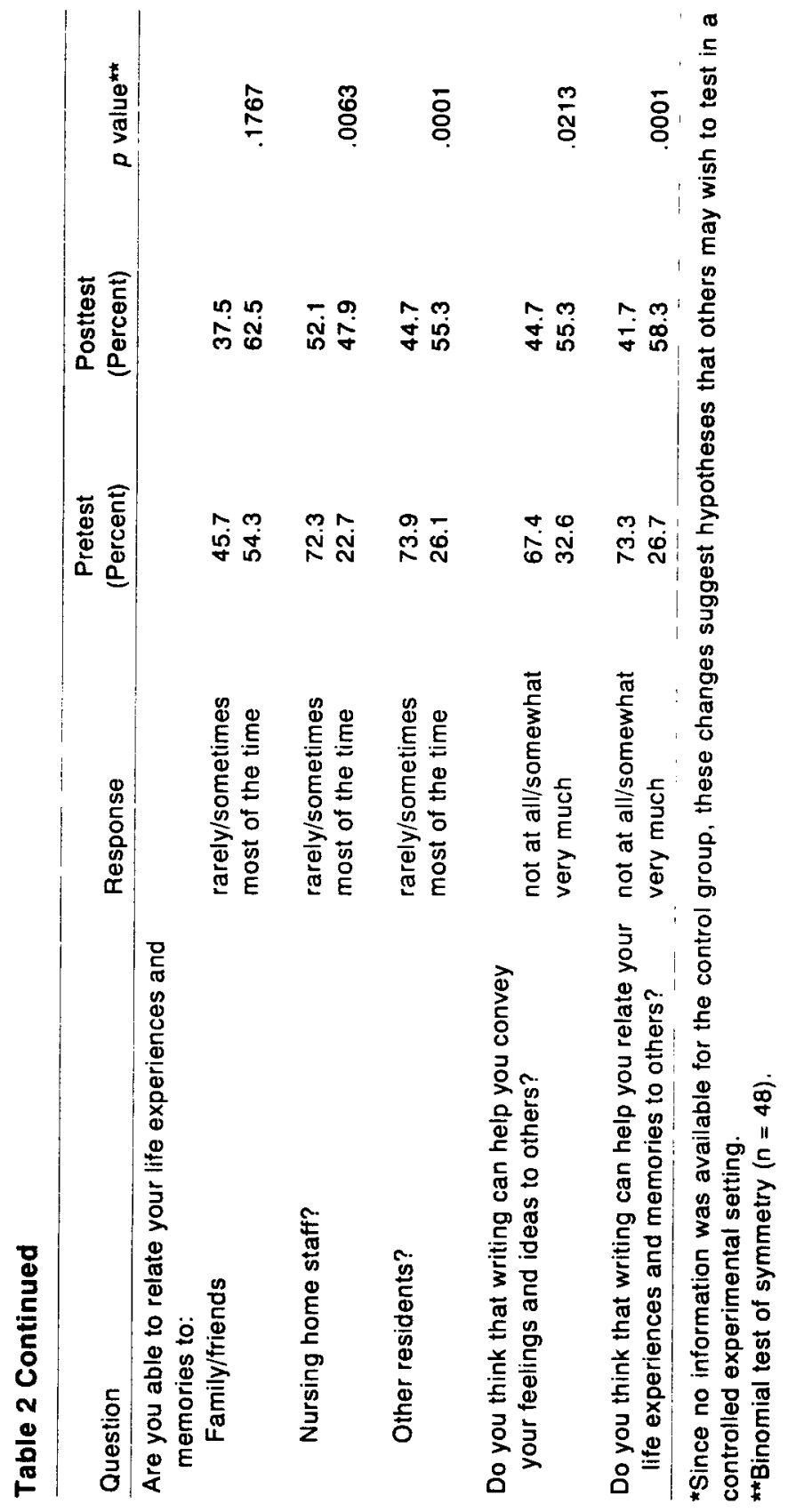


are due to chance. ${ }^{2}$ Different areas of improvement were observed in individual nursing homes, and no clear pattern emerged. Data were then stratified by level of function on MMS, DS, AB, and ADL measures. Of the participants with low MMS scores, several improved on awareness of self and others $(42.9 \%)$, interest $(42.9 \%)$, participation $(57.1 \%)$, and verbal communication (42.9\%). No improvement of this magnitude was found in high-MMS participants. Participants with high ADL scores demonstrated improvement in interest $(50.0 \%)$, participation (43.8\%), and relating to others (43.8\%); no corresponding changes were noted in low-ADL participants. No differentiation in group process measures was observed as a function of $\mathrm{DS}$ or $\mathrm{AB}$ scores.

\section{Discussion}

Previous study of writing groups has given little attention to the effectiveness of such activities for nursing home residents. The findings we report suggest that participation in writing groups does promote positive change and that predictions can be made as to which residents benefit most from participation.

It is striking that the control and experimental groups in our study were so similar not only in terms of demographic measures of age, ratio of women to men, education, and length of stay, but also across functional status measures. This similarity reduces concern that the use of a nonrandomized design may introduce selection bias, as the results show that no obvious bias exists. To the extent that the residents tested are similar to those of residents in other nursing homes, these results are generalizable.

The most notable change observed is the reduction in depression in writing group participants. It is difficult to ascertain whether this change is a result of the creative act of writing itself or the sense of community inherent in group process (Kaminsky, 1974); probably both contribute to the effect. That depression was affected is significant, as considerable research (Blazer, 1980; Busse \& Pfeiffer, 1977) has found pervasive levels of depression among nursing home residents.

Some conclusions may be drawn as to which residents benefit most from participation. With respect to depression, residents with higher cognitive ability, more depression, or higher affect show greatest improvement. Obviously the more depressed residents could show greater improvement, as those with less depression would show a ceiling effect 
on this measure; but it is significant that participation in an activity of relatively short duration could cause such a change. This concurs with the increasing awareness that depression is treatable (Blazer, 1980). Residents with higher cognitive and affective levels seem more able to benefit from the process and content of the group, at least with respect to a reduction in depression levels. Similarly, participants with low affect at pretesting show greater improvement in affect scores. Again, they had the most to gain, but this improvement does suggest that residents with a poor sense of well-being benefit from participation.

\section{Residents as Writers}

Before participating in the writing group, few residents had much experience with writing, and fewer still considered themselves writers. Findings from the writing group questionnaire support the perception of the instructor and volunteers that participants came to view themselves as writers. On completion of the group, significantly more participants were writing and using writing as a vehicle for problem resolution. In addition, participants were cnabled to relate feelings and ideas to other residents, and life experiences and memories to both residents and staff (Table 2). Clearly, the writing group successfully convinced participants that they could write and that their writing effectively conveyed their thoughts and feelings. Although the majority had done no writing previously, all participants wrote during the group, most wrote outside the group, and half discussed or shared their writings with others. The group definitely had value for those who participated, further supporting the concept of writing as enrichment. Residents actively engaged in meaningful roles as writers, empowered by the expression of their creative individuality.

\section{The Effect of Group Process}

Weekly assessments revealed the greatest improvement on group process measures for participants with low MMS scores and high ADL scores. One may assume that participants with high MMS scores at pretesting maintain high scores across the eight weeks and hence could not "improve" their scores. It is of interest, however, that participants with substantial cognitive impairment could show progress of this magnitude. That participants with high ADL scores improved across several measures suggests that they had preexisting, perhaps unex- 
pressed, abilities to function well in this type of activity. It is interesting that group process measures were not differentiated by DS or AB scores. The most likely explanation is that group process measures such as participation, interest, and enjoyment were quite broad and did not specifically assess the dimensions of affect and depression.

\section{Conclusion}

This initial group study demonstrates that participation in writing groups promotes positive change in nursing home residents, specifically those residents for whom such activities frequently are considered inappropriate - those without writing experience or "ability," the depressed, and the cognitively impaired. Many group participants achieved important gains: reduced depression in the depressed, improved group skills in the cognitively impaired, and a conviction of self as writer by the majority of the participants. These findings support the incorporation of writing groups in the range of activities provided in nursing homes; such groups are not a "frill" but appeal to and have value for a wide variety of residents. 


\section{Appendix: Writing Group Topics*}

\section{Session 1: Childhood Memories}

Hand-me-downs I (what was handed down)

Hand-me-downs II (what I'll hand down)

Session 2: Love

Advice to young lovers

That's a gift of love

Session 3: Seasons

I remember (season)

If I were (snow, sun ....)

Session 4: Music and Moods

I hear America singing

Session 5: Flowers

Favorite flowers

Who am I?

Session 6: Aging

I've lived long enough and I've learned...

Session 7: A Moment in Time

Memories of war

Memories of the Great Depression

Session 8: Letter writing

A letter to someone in the nursing home

$A$ response letter from the letter's recipient

*A complete curriculum is available on request to Katherine P. Supiano, Dept. of Internal Medicine, University of Michigan Medical Center, Turner Bldg., 1010 Wall St., Ann Arbor, MI 48109-0714.

\section{Notes}

1. Stratified Scores: low MMS $<20$; high MMS $\geq 20$; low DS $<12$; high DS $\geq 12$; low $A B$ $<6$; high $\mathrm{AB} \geq 6$.

2. The mechanism for comparison of group process scores is as follows:

a. Weekly, assign one of the following codes for each group process measure for each group participant.

$$
\begin{aligned}
& 1=\text { poor } \\
& 2=\text { fair } \\
& 3=\text { good }
\end{aligned}
$$


b. Add codes for first 4 weeks of writing group (period 1). This equals score 1.

c. Add codes for second 4 weeks writing group (period 2 ). This equals score 2 .

d. Subtract score 1 from score 2.

(1) If score 2 - score $1=1 ; 0$, or -1 , then the resident has "stayed the same" on this group process measure.

(2) If score 2 -score $1 \geq 2$ and if at least two weekly scores from period 2 are higher than weekly scores from period 1 , then the resident has "improved" on this group process measure.

(3) If score $2-$ score $1 \leq-2$, and if at least two weekly scores from period 2 are lower than weekly scores from period 1 , then the resident has "declined" on this group process measure.

\section{References}

Blazer, D. (1980). The diagnosis of depression in the elderly. Journal of the American Geriatrics Society, 28, 52.

Bradburn, N. M. (1969). The structure of psychological well-being. Chicago: Aldine.

Burnside, I. M. (1978). Form for evaluating patient's progress. In I. M. Burnside (Ed.), Working with the elderly: Group processes and techniques (p. 203). North Scituate, MA: Duxbury Press.

Busse, E. W., \& Pfeiffer, E. (1977). Functional psychiatric disorders in old age. In E. W. Busse and E. Pfeiffer (Eds.), Behavior and adaptation in late life (2nd ed., pp. 158-211). Boston: Little, Brown.

Campbell, R. (1984). The aging experience as reflected in creative writing. In S. F. Spicker \& S. R. Ingman (Eds.), Vitalizing long-term care: The teaching nursing home and other perspectives (pp. 128-156). New York: Springer.

Campbell, R. (1985). Writing groups with the elderly. In M. Sundel \& P. Glasser (Eds.), Individual change through small groups (2nd ed., pp. 546-559). New York: Free Press.

Coberly, L. M., McCormick, J., \& Updike, K. (1984). Writers have no age: Creative writing with older adults. New York: Haworth Press.

Folstein, M. F., Folstein, S., \& McHugh, P. R. (1975). Mini-mental state: A practical method for grading the cognitive state of patients for the clinician. Journal of Psychiatric Research, 12, 189-198.

Getzel, G. (1984). Old people, poetry and groups. In M. Kaminsky (Ed.), The uses of reminiscence: New ways of working with older adults (pp. 193-199). New York: Haworth Press.

Kaminsky, M. (1974). What's inside you, it shines out of you. New York: Horizon Press.

Kaminsky, M. (1984). The uses of reminiscence: A discussion of the formative literature. In M. Kaminsky (Ed.), The uses of reminiscence: New ways of working with older adults (pp. 137-165). New York: Haworth Press.

Koch, K. (1977). I never told anybody: Teaching poetry writing in a nursing home. New York: Random House.

Linn, M. W. (1967). A rapid disability rating scale. Journal of the American Geriatrics Society, 15, 211-214.

Moriwake, S. Y. (1974). The Affect-Balance Scale: A validity study with aged samples. Journal of Gerontology 29, 73-78. 
Neter, J., \& Wasserman, W. (1974). Applied linear statistical models: Regression, analysis of variance, and experimental designs. Homcwood, IL: Richard D. Irwin.

Shore, H. (1978). Group programs in long-term care facilities. In I. M. Burnside (Ed.), Working with the elderly: Group processes and techniques (pp. 344-355). North Scituate, MA: Duxbury Press.

Yesavage, J. A., Brink, T. L., Lum, O., Huang, V., Adey, M., \& Leirer, V. O. (1983). Development and validation of geriatric depression screening scale: A preliminary report. Journal of Psychiatric Research, 17 (1), 37-49.

Katherine P. Supiano, M.S., is the Writing Coordinator for the Turner Geriatric Services Nursing Home Enrichment Program. She has conducted creative writing classes in 11 nursing homes and one geriatric psychiatric hospital, edited 12 anthologies of class writings, and developed a training manual for writing instructors.

Ronald J. Ozminkowski, M.H.S.A., M.A.A.E., performed the statistical analyses for this project. He is currently a Staff Research Fellow in the Hospital Studies Program of the National Center for Health Services Research, and conducts research on hospital costs, utilization, and economic behavior.

Ruth Campbell, M.S.W., is the Director of Turner Geriatric Services Social Work Department and a Faculty Associate of the University of Michigan Institute of Gerontology. She is currently on a Fulbright Fellowship with the Tokyo Metropolitan Institute of Gerontology and is studying Japanese elderly and family relations.

Carole Lapidos, M.S.W., is the Project Director of the Nursing Home Enrichment Program, and has developed memory stimulation and interactive drama classes. 